\title{
COMPROMISO CON LA INVESTIGACIÓN Y LAS POLÍTICAS SOCIALES
}

n esta edición número 11 de la revista Palobra, Palabra que Obra,
aspiramos a continuar con el proceso de su integración a sistemas de
información, como el caso de la Red de Revista Científicas de América
Latina, el Caribe, España y Portugal REDALYC, y seguir ofreciendo un
producto de calidad y que refleje los avances científicos de autores nacionales
e internacionales, pero sobre todo, locales.

En esta oportunidad se registran siete artículos de profesores de la Universidad de Cartagena, tres de autores de universidades nacionales y dos más de universidades internacionales, a fin de ofrecer no sólo diversas miradas de los fenómenos sociales desde los contextos en que se originan sino además, hacer de Palobra una revista cada vez más abierta a mostrar los resultados investigativos de una amplia comunidad científica.

En "La cuestión social como cuestión nacional, una mirada genealógica", su autor el profesor Alfredo Carballeda de la Universidad Nacional de la Plata y Universidad de Buenos Aires (Argentina), presenta un análisis histórico acerca del concepto de cuestión social, entendido como categoría de análisis que implica, acceder a diferentes maneras de comprenderlo y explicarlo, para estudiarlo en función a la forma más apropiada de entender los diferentes fenómenos vinculados con los problemas sociales en América Latina, así como su relación con el horizonte de la intervención social, la comprensión de los problemas sociales y el análisis de estos.

En "Las políticas e intervenciones sociales. Algunas consideraciones éticas", la profesora Liliana Pérez Mendoza de la Universidad de Cartagena, presenta una reflexión acerca de los objetivos que las políticas sociales deben asumir hoy, en torno a la restauración de la ciudadanía a partir del acceso a derechos sociales de los sujetos y la dinamización del vínculo o tejido social, a fin de construir una sociedad más democrática, participativa, corresponsable, solidaria y con claros principios éticos en las diferentes realidades socio-culturales.

En el artículo "La población desplazada en Cartagena de Indias: alcances y limitaciones de la política pública" de los autores Amaranto Daniels, Raúl Román y Jennifer Jiménez, presentan los alcances y limitaciones que ha tenido

Palubra No. 11. Septiembre de 2009 - Agosto de 2010 
la política pública sobre la población desplazada en la ciudad de Cartagena y evalúa las condiciones de vulnerabilidad que enfrenta esta población frente a las precariedades que tiene el gobierno distrital para hacer frente a su grave situación de exclusión, rechazo e inserción social.

En "Pobreza en un reasentamiento voluntario de población desplazada: caso Patio Grande", el profesor Camilo Rey Sabogal de la Universidad de Cartagena, mediante una investigación evalúa la situación de un grupo de 39 familias en condición de desplazamiento que se reasentaron de forma voluntaria en la Finca Patio Grande (San Jacinto- Bolívar), mostrando que después de siete años de reasentamiento ningún hogar ha logrado superar la pobreza y el 76\% aún recibe ingresos inferiores a la línea de indigencia, como consecuencia de las condiciones de vulnerabilidad y marginalización de las víctimas por su calidad de desplazados, de campesinos y de reasentados en la zona rural de un municipio muy pobre, ajeno a sus múltiples y diversas raíces.

En el artículo "La genética del discurso del desarrollo. Explorando alternativas reales" su autor Juan Masullo, presenta un análisis crítico desde la perspectiva de las formaciones discursivas de Michel Foucault, de la transformación que sufrió la noción de desarrollo durante la segunda postguerra, con la intención de señalar la manera en que se formó el discurso del desarrollo y se hizo hegemónico, aportando a su deconstrucción y dirigiendo la crítica a la idea misma de desarrollo, a fin de impulsar alternativas reales para este.

La profesora Mary Pattillo de la Universidad de Pittsburg (E.U.) en su artículo "La posición intermediaria de los afroamericanos de clase social media en Estados Unidos" mediante una investigación etnográfica de un barrio negro en la ciudad de Chicago, demuestra cómo los afroamericanos de clase media manejan este rol intermediario y cómo es posible que sus intervenciones puedan mejorar o perjudicar el bienestar de los afrodescendientes más vulnerables, para ello analiza la posición socioeconómica de los afroamericanos en comparación con los blancos y entre sí en Estados Unidos y reflexiona acerca del rol sociopolítico de la clase social media y media alta negra dentro de la comunidad negra, que a pesar de su éxito, sigue experimentando desventajas con respeto a los blancos.

En el articulo "¿Raizales, pañas, fifty, turcos o isleños?: Construcción de identidades en un contexto multiétnico", su autora Silvia Torres analiza cómo en un contexto multiétnico, como el de la Isla de San Andrés, el reconocimiento de la etnia raizal aunque se considere válido, conlleva a 
situaciones problemáticas, tales como la tendencia a resaltar los valores de la cultura raizal por encima de los otros grupos étnicos que cohabitan en la isla, en la medida en que invisibiliza las otras formas de ser isleños, tales como los isleños hijos de los continentales y extranjeros nacidos en la isla y descendientes de población raizal y otros grupos culturales, que se dieron como consecuencia del proceso migratorio a partir de la declaratoria del Puerto Libre.

Las profesoras Nadia Morales y Pilar Garzón de la Universidad de San Buenaventura (Cartagena) en el artículo "Las festividades novembrinas del municipio de Turbo: un modo de ser caribe", presentan un análisis de las festividades novembrinas del municipio de Turbo y el sentido que estas adquieren para los turbeños de origen bolivarense. Se indaga sobre las distintas actividades culturales que entran en escena en estas fiestas novembrinas turbeñas que resaltan y reafirman un modo de ser caribeño.

La profesora Clara Fonseca Mendoza de la Universidad de Cartagena, en su artículo "Discursivas de representación de género en la música de acordeón", apoyada en los resultados de su investigación, y bajo el supuesto que los usos del lenguaje reflejan y construyen valores ideológicos, presenta algunos discursos que transmiten estereotipos de género en la música de acordeón marcados por ciertas estructuras de poder, algunas de las cuales son los tópicos que plantean relaciones entre hombres y mujeres, el vocabulario que los clasifica, los procesos en que participan y sus roles en estos.

Los profesores Germán Betancourth y Elena Calvo de la Universidad de Cartagena, en su artículo "Mecanismos performativos del género como poder: La ortopedia social y la normalización de la masculinidad", desvinculan la relación del género como construcción, y abordan la noción de materialización como elemento que permite revisar este concepto como agente productor de los cuerpos que intenta controlar y describir. Explica el género como el resultado de un poder en si mismo que fabrica los sujetos con género, establece las interpretaciones de los cuerpos, da coherencia a las normativas heterosexuales de masculinidad y feminidad, y a su vez permite la configuración de mecanismos de normalización a través de procesos de castigo y vigilancia.

El profesor José Márquez Estrada en su artículo "La imposible prisión. Sistema penitenciario y carcelario en el Estado Soberano de Bolívar: 1860-1880",

Palubra No. 11. Septiembre de 2009 - Agosto de 2010 
muestra las diferentes circunstancias por las que pasó el Estado Soberano de Bolívar con relación al proceso de construcción de un aparato penitenciario y carcelario entre 1860 y 1880, así como las diferentes estrategias que se intentaron implementar para saldar el problema financiero que se presentó en la construcción de dicho sistema penitenciario. Se describen los diferentes acontecimientos que se vivieron en las distintas provincias que conformaban el Estado en relación a la vida en las cárceles, la situación de los reos, los dispositivos educativos y productivos impulsados dentro de los penales, los conflictos, las situaciones de inseguridad y de hacinamiento, las fórmulas de solución aplicadas, los fracasos y los mecanismos de control y de regulación de la vida carcelaria impulsados para corregir el mal funcionamiento de estas instituciones.

Los profesores de la Universidad de Cartagena, Juan Carlos Vergara, Tomás Fontalvo y Francisco Maza, en el documento "Futurología: origen, evolución y métodos", muestran mediante una revisión bibliográfica y de investigaciones el origen, conceptos y teorías que giran alrededor de la futurología, que con más de 60 años de haber sido concebida como el ideal de una ciencia encargada de prever lo que deparará el futuro, ha intentado plantear un método perfecto para realizar predicciones válidas sobre el futuro. Además, recrean sus distintos métodos o herramientas para la planeación por escenarios.

En Notas de aquí...y Notas de Allá se presentan los eventos y trabajos donde han participado docentes y estudiantes, así como los convenios de cooperación firmados por la Universidad de Cartagena y en los cuales la Facultad de Ciencias Sociales y Educación ha intervenido.

Convencidos que la Revista Palobra es una plataforma para colocar en discusión y en la agenda pública diversos y complejos temas sociales actuales, esperamos estimado lector, que los mismos sean de su interés y contribuyan a posicionar el esfuerzo editorial de la Universidad de Cartagena a escala nacional e internacional.

La Editora 